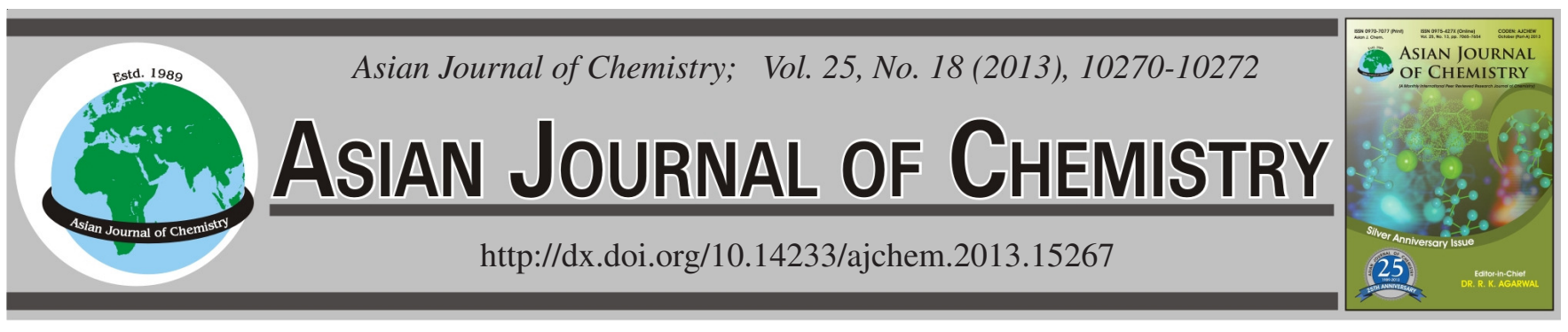

\title{
Solid Phase Extraction of Palladium Uusing Microspheres Containing Hexyl Benzimidazolyl Sulphide as Sorbent
}

\author{
Cong Li, Zhangue Huang* and Jing Chen
}

Department of Chemistry, Yunnan University, Kunming 650091, P.R. China

*Corresponding author: Fax: +86 871 5032180; E-mail: zhjhuang@ynu.edu.cn

The extraction of palladium(II) from hydrochloric acid medium was carried out using the microspheres containing hexyl benzimidazolyl sulphide as an extractant. Adsorption capacities under optimum conditions were determined. The Pd(II) ions adsorption capacities increased by increased hexyl benzimidazolyl sulphide content and initial $\mathrm{Pd}(\mathrm{II})$ ions concentration and it reached the maximum value at $0.4 \mathrm{~g} \mathrm{L^{-1 }}$ initial Pd(II) ions concentration under the determined optimum conditions. Successful striping of palladium(II) from the microspheres were achieved with $0.8 \mathrm{~mol} \mathrm{~L}^{-1}$ thiourea solution. The microspheres can be reused at least in 20 cycles of extraction-stripping process.

Key Words: Palladium, Solid phase extraction, Microspheres, Hexyl benzimidazolyl sulphide.

\section{INTRODUCTION}

As an important member of platinum group metals, palladium is of great value in modern industry due to its favourable physical and chemical properties, such as high melting point, corrosion resistance and extraordinary catalytic ability $^{1-3}$.

For the stable supply of palladium and minimizing its waste, it is necessary to develop an effective recovery technique of palladium. The solvent extraction method has been used for the recovery of precious metals. The solvent extraction method has a high selectivity and is easy to scale-up, but the solvent extraction method uses large amounts of organic solvents. Thus the solvent extraction processes may adversely affect the environment and human body ${ }^{4-8}$. To solve these problems, the solid phase extraction (SPE) have been investigated. Solid phase extraction has emerged as an excellent separation technique in recent years in comparison to traditional extraction methodologies because of its numerous advantages of high enrichment factor, better separation, high selectivity and efficiency, ease of recovery and reusability, low cost because of lower consumption of reagents, less utilization of organic solvents and more importantly environment friendly ${ }^{9-17}$. In the present work, a new sorbent, the microspheres containing hexyl benzimidazolyl sulphide (HBMS) have been evaluated for the extraction of palladium(II) from hydrochloric acid medium. The effect of various parameters such as hexyl benzimidazolyl sulphide content, concentration of hydrochloric acid and palladium ion on extraction of palladium has been studied.

\section{EXPERIMENTAL}

A Z-2000 polarized zeeman atomic absorption spectrophotometer (Hitachi High-Technologies Corporation, Japan) was used to measure the concentration of Pd(II). The operating conditions were carried out according to the recommendations of manufacturer. The wavelengths selected was at $247.6 \mathrm{~nm}$ for palladium.

Divinylbenzene (DVB), methyl methacrylate (MMA), azobisisobutyronitrile (AIBN), cyclohexane and sodium dodecyl benzene sulfonate (SDBS) (analytical grade) were purchased from Beijing Chemical Reagent Co. Palladium(II) stock solution $\left(1.0 \mathrm{~g} \mathrm{~L}^{-1}\right)$ was prepared as described. A weighed portion of palladium metal was dissolved in aqua regia (120 $\mathrm{mL}$ ). When the metal was completely dissolved, the solution was evaporated to nearly dryness. Residual $\mathrm{HNO}_{3}$ was removed by adding $30 \mathrm{~mL}$ of $6 \mathrm{~mol} \mathrm{~L}^{-1} \mathrm{HCl}$ and evaporated to nearly dryness again and this was repeated 3 times. The solution was transferred into a $250 \mathrm{~mL}$ of volumetric flask and the final norm volume was adjusted by adding $0.1 \mathrm{~mol} \mathrm{~L}^{-1} \mathrm{HCl}$ solution. Hexyl benzimidazolyl sulphide (HBMS) was synthesized in our laboratory as reported method ${ }^{18}$. Divinylbenzene was purified by washing with a $10 \%$ sodium hydroxide aqueous solution. Other chemicals were all commercially available reagents of analytical grade.

Preparation of the microspheres: The microspheres containing HBMS were prepared by suspension polymerization technique. In a typical procedure, the organic phase was prepared by dissolution of MMA and HBMS in cyclohexane. Furthermore, 
the divinylbenzene and azobisisobutyronitrile (AIBN) were also added into this organic phase mixture. Continuous phase (dispersion or suspension medium) was prepared by dissolution of sodium dodecyl benzene sulfonate (SDBS) as a stabilizer in distilled water. These two phases were combined in the reactor and then heated at $80{ }^{\circ} \mathrm{C}$ with stirring at $420 \mathrm{rpm}$ for $6 \mathrm{~h}$ under the nitrogen atmosphere. The prepared microspheres were collected by filtration, washed with distilled water, dried under vacuum and sieved to get particles lower than $150 \mu \mathrm{m}$.

Solid-phase extraction of Pd(II): In the adsorption of Pd(II) ions, first of all, the initial HBMS amount used in the preparation of the microspheres was changed between 0 and $49 \%(w / w)$ as the most effective parameter. Other effective parameters on the adsorption of $\mathrm{Pd}(\mathrm{II})$ ions were selected as the acidity of the adsorption medium and initial Pd(II) concentration. The experiments for the investigation of the effects of these parameters were carried out by using $49 \%(\mathrm{w} / \mathrm{w})$ of initial HBMS amount since the maximum adsorption capacity was reached for this value under the determined optimum experimental conditions. During these studies, the acidity of the adsorption medium was adjusted by using diluted $\mathrm{HCl}$ solutions. The volume of the adsorption medium and the amount of the microspheres were kept as $100 \mathrm{~mL}$ and $0.50 \mathrm{~g}$, respectively, in all studies. Adsorption studies were batchwise type and were performed at room temperature. After phase separation, the concentration of $\mathrm{Pd}(\mathrm{II})$ in aqueous solution was determined by an atomic absorption photometer. These results were further used to estimate the extraction efficiency of $\mathrm{Pd}(\mathrm{II})$ ions. The amount of extracted $\mathrm{Pd}(\mathrm{II})$ ions was calculated according to the differences in the Pd(II) ions concentrations of the aqueous phase between, before and after the extraction. Adsorption capacities of the microspheres for Pd (II) ions were calculated by following equation:

$$
\mathrm{Q}=\frac{\left(\mathrm{C}_{0}-\mathrm{C}_{\mathrm{e}}\right) \mathrm{V}}{\mathrm{W}}
$$

where $\mathrm{Q}$ is the loading capacity of the microspheres $\left(\mathrm{mg} \mathrm{g}^{-1}\right)$ $\mathrm{C}_{0}$ and $\mathrm{C}_{\mathrm{e}}$ are the concentrations of the $\mathrm{Pd}(\mathrm{II})$ ions in the initial solution and in the aqueous phase after adsorption, respectively $\left(\mathrm{mg} \mathrm{L}^{-1}\right) ; \mathrm{V}$ is the volume of the aqueous phase $(\mathrm{L})$ and $\mathrm{W}$ is the amount of the microspheres $(\mathrm{g})$.

\section{RESULTS AND DISCUSSION}

Effect of hexyl benzimidazolyl sulphide content: The first effective parameter on the $\mathrm{Pd}(\mathrm{II})$ ions adsorption of the microspheres was selected as HBMS content of the microspheres. During the preparation of the microspheres, the HBMS content was changed between 0 and $49 \%$ (w/w) for a typical procedure to prepare different the microspheres with different HBMS contents. Hydrochloric acid concentration of the adsorption medium was $0.1 \mathrm{~mol} \mathrm{~L}^{-1}$, initial $\mathrm{Pd}(\mathrm{II})$ concentration was $0.4 \mathrm{~g} \mathrm{~L}^{-1}$ and adsorption time was fixed as $2 \mathrm{~h}$ (this time is the saturation value for $\mathrm{Pd}(\mathrm{II})$ ion adsorption onto the microspheres). The obtained results are shown in Fig. 1. Palladium(II) ion adsorption capacity increased by increasing HBMS content of the microspheres as shown in Fig. 1. Minimum $\mathrm{Pd}(\mathrm{II})$ ion adsorption was obtained with the microspheres (without HBMS groups) (i.e., $3 \mathrm{mg} \mathrm{g}^{-1}$ the microspheres) and maximum adsorption was achieved using the microspheres

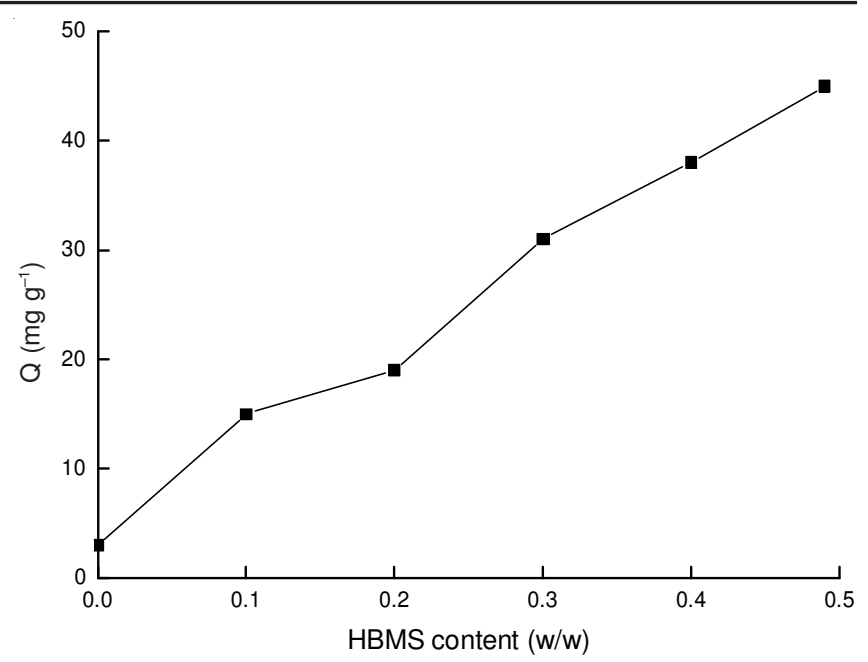

Fig. 1. Effect of HBMS content over the Pd(II) ion adsorption. sample volume: $100 \mathrm{~mL}, \mathrm{Pd}(\mathrm{II})$ concentration: $0.4 \mathrm{~g} \mathrm{~L}^{-1}$, $\mathrm{HCl}$ concentration: $0.1 \mathrm{~mol} \mathrm{~L}^{-1}$, the amount of the microspheres: $0.5 \mathrm{~g}$

(i.e., $45 \mathrm{mg} \mathrm{g}^{-1}$ the microspheres) with the highest HBMS content (i.e., $49 \%, \mathrm{w} / \mathrm{w}$ ) as expected.

Influences of hydrochloric acid concentration: In industrial application for extraction of $\mathrm{Pd}(\mathrm{II})$, the acidity of the adsorption medium usually influences significantly. Hydrochloric acid concentration of the adsorption medium was changed from 0.1 to $2 \mathrm{~mol} \mathrm{~L}^{-1}$. In the study, initial Pd(II) ion concentration was used as $0.4 \mathrm{~g} \mathrm{~L}^{-1}$ and the saturation time was defined as $2 \mathrm{~h}$. Pd(II) ion adsorption values are shown in Fig. 2. The adsorption capacity of the microspheres was very low at the highly acidic medium. Quantitative extraction of palladium occurred at $0.1 \mathrm{~mol} \mathrm{~L}^{-1} \mathrm{HCl}$. Therefore, $0.1 \mathrm{~mol} \mathrm{~L}^{-1}$ $\mathrm{HCl}$ was adopted in all subsequent experiments.

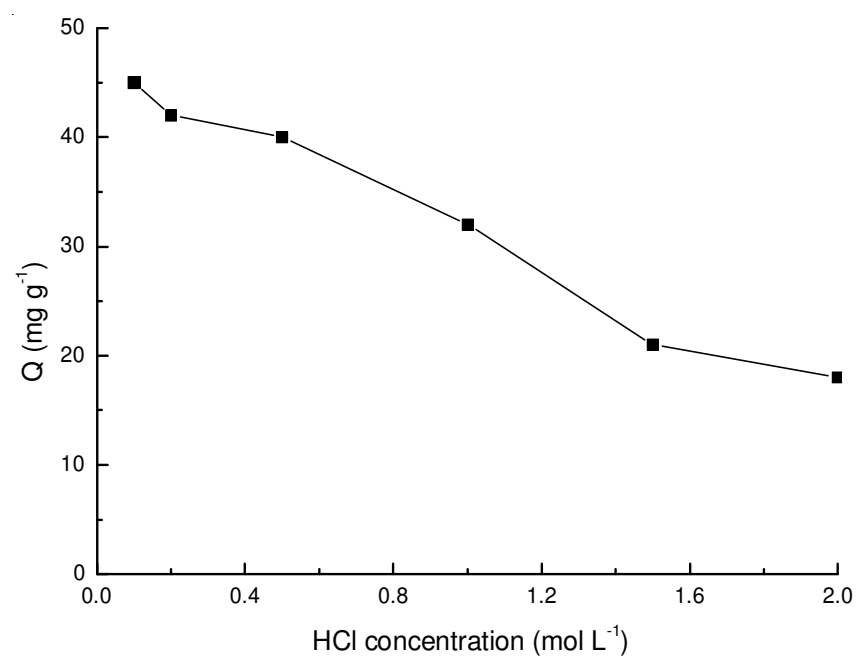

Fig. 2. Effect of the acidity over the Pd(II) ion adsorption. sample volume: $100 \mathrm{~mL}, \mathrm{Pd}(\mathrm{II})$ concentration: $0.4 \mathrm{~g} \mathrm{~L}^{-1}$, the amount of the microspheres: $0.5 \mathrm{~g}$

Influences of initial metal ion concentration: The effect of initial $\mathrm{Pd}(\mathrm{II})$ ion concentration on the $\mathrm{Pd}(\mathrm{II})$ ion adsorption with the microspheres was evaluated. The microspheres with the highest HBMS content (i.e., $49 \%$,w/w) were used in these studies. The obtained adsorption results are shown in Fig. 3. The Pd(II) ion adsorption capacity was increased by increasing 


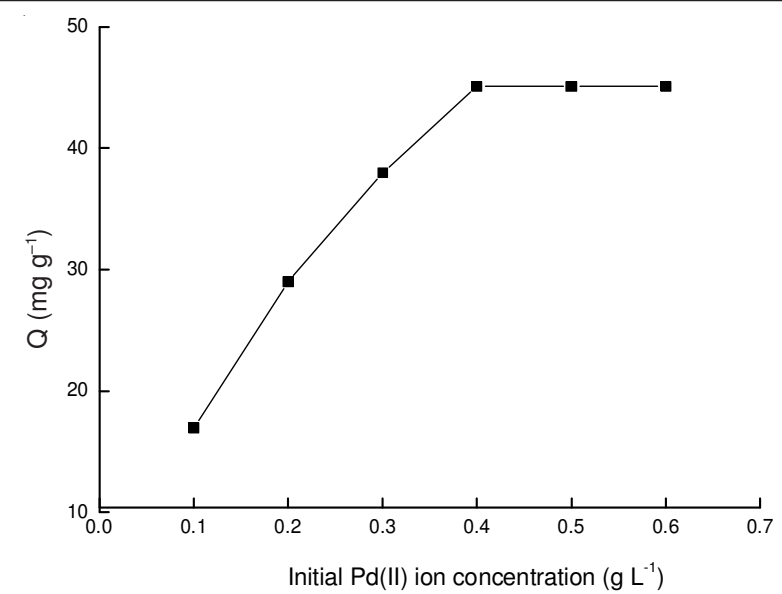

Fig. 3. Effect of the initial Pd(II) ion concentration over the $\mathrm{Pd}(\mathrm{II})$ ion adsorption. sample volume: $100 \mathrm{~mL}, \mathrm{HCl}$ concentration: $0.1 \mathrm{~mol}$ $\mathrm{L}^{-1}$, the amount of the microspheres: $0.5 \mathrm{~g}$

the initial $\mathrm{Pd}(\mathrm{II})$ ion concentration and it reached the maximum value (i.e., $45 \mathrm{mg} \mathrm{g}^{-1}$ the microspheres) at $0.4 \mathrm{~g} \mathrm{~L}^{-1}$ initial $\mathrm{Pd}(\mathrm{II})$ ion concentration. Further increasing the initial $\mathrm{Pd}(\mathrm{II})$ ion concentration from 0.4 to $0.6 \mathrm{mg} \mathrm{L}^{-1}$, The Pd(II) ion adsorption capacity kept constant. Therefore, the maximum adsorption capacity of the microspheres was $45 \mathrm{mg} \mathrm{g}^{-1}$ for palladium.

Desorption and reusability studies: Palladium loaded in the microspheres was stripped with various stripping agents, such as thiourea, hydrochloric acid, nitric acid, sodium hydroxide, ammonia and sodium sulfite as stripping agents. In the following experiments, hydrochloric acid concentration of the adsorption medium was $0.1 \mathrm{~mol} \mathrm{~L}^{-1}$, initial $\mathrm{Pd}(\mathrm{II})$ ion concentration was $0.4 \mathrm{~g} \mathrm{~L}^{-1}$ and HBMS content of the microspheres was $49 \%(\mathrm{w} / \mathrm{w})$ in all experiments of this part of the study. The volumes of the adsorption and desorption media were both kept constant as $100 \mathrm{~mL}$. Desorption time was fixed as $1 \mathrm{~h}$. The results show that palladium can not be stripped from the microspheres with acid solution and sodium hydroxide. Thiourea solution can be used as the effective stripping agent. As can be seen from Fig. 4, by increasing thiourea concentration from $0.2-0.8 \mathrm{~mol} \mathrm{~L}^{-1}$, the percentage stripping of $\mathrm{Pd}(\mathrm{II})$ increased from $67.2-98.8 \%$. By further increasing concentration of thiourea from $0.8-1.2 \mathrm{~mol} \mathrm{~L}^{-1}$, the percentage stripping of $\mathrm{Pd}(\mathrm{II})$ kept constant. The stripping was quantitative when $0.8 \mathrm{~mol} \mathrm{~L}^{-1}$ thiourea solution was used.

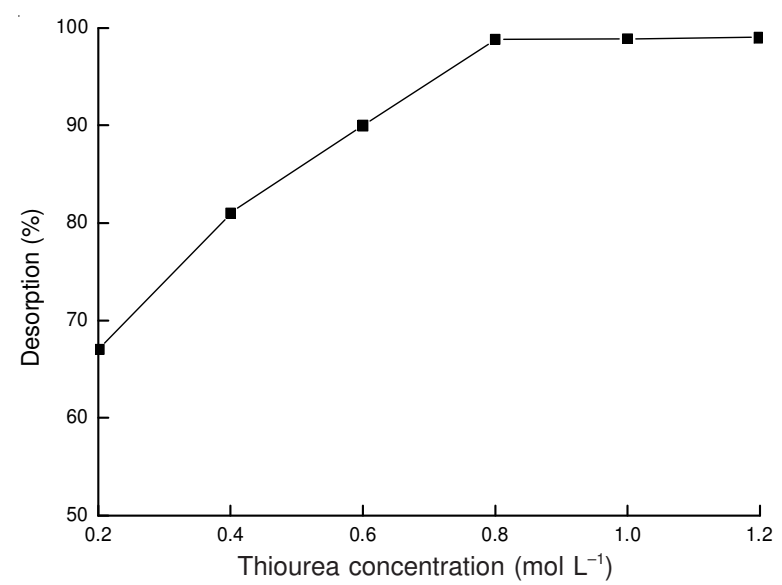

Fig. 4. Influence of thiourea concentration on the elution of $\operatorname{Pd}(\mathrm{II})$ from the microspheres. elution volume: $100 \mathrm{~mL}$, desorption time: $1 \mathrm{~h}$
Reusability of the adsorbents is one of the most important considerations in the adsorption and removal studies of the $\mathrm{Pd}(\mathrm{II})$. At the end of the adsorption-desorption studies, the microspheres were washed with the $0.8 \mathrm{~mol} \mathrm{~L}^{-1}$ thiourea solution first and then with distilled water for three times for $5 \mathrm{~min}$ in all adsorption-desorption steps. The adsorption capacity of the microspheres had no considerable decrease after 20 cycles of repeated experiments. The microspheres showed good reusability and stability towards $\mathrm{Pd}(\mathrm{II})$.

\section{Conclusion}

The microspheres containing hexyl benzimidazolyl sulphide were synthesized and studied as a novel sorbent for palladium from hydrochloric acid medium. Suspension polymerization method was used in the prepration of microspheres. Extractant capacities of the microspheres for the extractant of $\operatorname{Pd}(\mathrm{II})$ ions from hydrochloric acid solutions under optimum conditions were determined. The Pd(II) ions extractant capacities increased by increased hexyl benzimidazolyl sulphide content and initial $\mathrm{Pd}(\mathrm{II})$ ions concentration under the determined optimum conditions. The microspheres were found to be reusable after desorption for several times.

\section{ACKNOWLEDGEMENTS}

This work was supported by the National Natural Science Foundation of China (51264038), Key Natural Science Foundation of China (U0937601), Development Program of China (2011AA03A405D) and Science and Technology Support Program of China (2008BAB32B10).

\section{REFERENCES}

1. H. Sharififard, M. Soleimani and F.Z. Ashtiani, J. Taiwan Inst. Chem. Eng., 43, 696 (2012).

2. F.F. Bai, G. Ye, G.J. Chen, J.C. Wei, J.C. Wang and J. Chen, Sep. Purif. Technol., 106, 38 (2013).

3. R. Kumaresan, K.N. Sabharwal, T.G. Srinivasan, P.R.V Rao and G. Dhekane, Solvent Extr. Ion Exch., 26, 643 (2008).

4. J.M. Sanchez, M. Hidalgo and V. Salvado, Solvent Extr. Ion Exch., 22, 285 (2004).

5. E. Guibal, V.O.N. Sweeney, T. Vincent and J.M. Tobin, React. Funct. Polym., 50, 149 (2002).

6. Z. Tu, S. Lu, X. Chang, Z. Li, Z. Hu, L. Zhang and H. Tian, Microchim. Acta, 173, 231 (2011).

7. J. Traeger, J. Konig, A. Stadtke and H.J. Holdt, Hydrometallurgy, 127128, 30 (2012).

8. R.K. Sharma, A. Pandey, S. Gulati and A. Adholeya, J. Hazard. Mater., 209-210, 285 (2012).

9. R.J. Li, Q. He, Z. Hu, S.R. Zhang, L.J. Zhang and X.J. Chang, Anal. Chim. Acta, 713, 136 (2012).

10. E. Mladenova, I. Dakova, I. Karadjova and M. Karadjov, Microchem. J., 101, 59 (2012).

11. K. Mehrani, A. Mehrani, M. Amini, O. Sadeghi and N. Tavassoli, Microchim. Acta, 173, 521 (2011).

12. S. Sivrikaya, H. Altundag, M. Zengin and M. Imamoglu, Sep. Sci. Technol., 46, 2032 (2011).

13. R. Ruhela, K.K. Singh, B.S. Tomar, J.N. Sharma, M. Kumar, R.C. Hubli and A.K. Suri, Sep. Purif. Technol., 99, 36 (2012).

14. C. Yuan, Y. Zhang, S. Wang and A. Chang, Microchim. Acta, 173, 361 (2011).

15. B. Godlewska-Zylkiewicz, B. Lesniewska and I. Wawreniuk, Talanta, 83, 596 (2010).

16. Z.J. Huang, X.G. Wang and Z.Q. Yang, Anal. Lett., 43, 876 (2010).

17. Z.J. Huang, X.G. Wang and J. Chang, Asian J. Chem., 22, 365 (2010).

18. Z.J. Huang, J. Chang, S.P. Feng and Z.Q. Yang, Asian J. Chem., 22, 2018 (2010). 